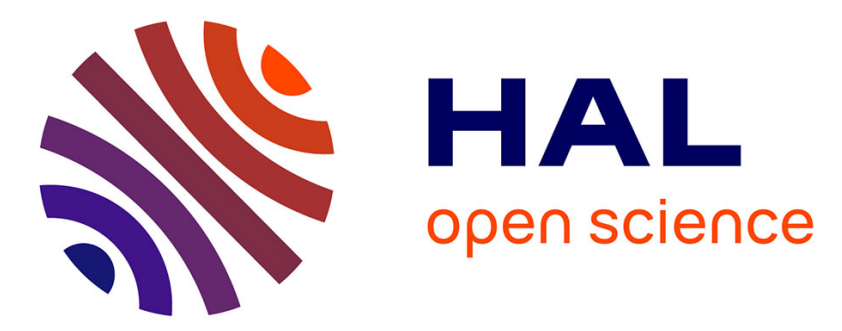

\title{
Cell-wall polysaccharides from the marine green alga Ulva "rigida" (Ulvales, Chlorophyta) - NMR analysis of ulvan oligosaccharides
}

\author{
Marc Lahaye, Benjamin Ray
}

\section{- To cite this version:}

Marc Lahaye, Benjamin Ray. Cell-wall polysaccharides from the marine green alga Ulva "rigida" (Ulvales, Chlorophyta) - NMR analysis of ulvan oligosaccharides. Carbohydrate Research, 1996, 283, pp.161-173. hal-02694190

\section{HAL Id: hal-02694190 \\ https://hal.inrae.fr/hal-02694190}

Submitted on 1 Jun 2020

HAL is a multi-disciplinary open access archive for the deposit and dissemination of scientific research documents, whether they are published or not. The documents may come from teaching and research institutions in France or abroad, or from public or private research centers.
L'archive ouverte pluridisciplinaire HAL, est destinée au dépôt et à la diffusion de documents scientifiques de niveau recherche, publiés ou non, émanant des établissements d'enseignement et de recherche français ou étrangers, des laboratoires publics ou privés. 


\title{
Cell-wall polysaccharides from the marine green alga Ulva "rigida" (Ulvales, Chlorophyta) NMR analysis of ulvan oligosaccharides ${ }^{1}$
}

\author{
Marc Lahaye ${ }^{*}$, Bimalendu Ray ${ }^{2}$ \\ INRA, Laboratoire de Biochimie et Technologie des Glucides, BP 1627, Nantes 44316 Cedex 03, France
}

Received 19 October 1995; accepted 14 December 1995

\begin{abstract}
In order to obtain information on sugar sequences in the water soluble polysaccharides from Ulva "rigida", oligosaccharides were purified by anion exchange and gel permeation chromatography from the partial acid hydrolysate of the native or desulfated ulvan. The chemical structure and sugar sequence of these oligomers were determined by ${ }^{1} \mathrm{H}$ and ${ }^{13} \mathrm{C}$ NMR spectroscopy to be $\alpha$-L-rhamnosyl $(1 \rightarrow 4)$ D-xylose, $\beta$-D-glucuronosyluronic acid $(1 \rightarrow 2)$ - $\alpha$-L-rhamnosyl $(1 \rightarrow 4)$ D-xylose, $\beta$-D-glucuronosyluronic acid $(1 \rightarrow 4)$ L-rhamnose 3 sulfate, $\beta$-D-glucuronosyluronic acid $(1 \rightarrow 4)$ [ $\beta$-D-glucuronosyluronic acid $(1 \rightarrow 2)]$ L-rhamnose and $\beta$-D-glucuronosyluronic acid $(1 \rightarrow 4)[\beta$-D-glucuronosyluronic acid $(1 \rightarrow 2)] \alpha$-L-rhamnosyl $(1 \rightarrow 4)$ D-xylose. The sugar linkages and particularly the branching and the sulfate position were in total agreement with previous chemical results.
\end{abstract}

Keywords: Ulva; Chlorophyceae; Algae; Ulvan; NMR spectroscopy; Oligosaccharides

\section{Introduction}

The cell wall of the marine green algae Ulva "rigida" is composed of a water-soluble sulfated glucuronorhamnoxyloglycan (referred to as ulvan for simplicity), alkalisoluble linear $\beta-1,4$ glucoxylan, and $\beta$-1,4-glucuronan [1,2]. The alkali-insoluble

\footnotetext{
* Corresponding author.

'Part 3 of the series Cell-wall polysaccharides from the marine green alga Uva "rigida" (Ulvales, Chlorophyta).

${ }^{2}$ Present address: University of Burdwan, USIC-CIF, Burdwan 713104, India.
} 
polysaccharides of a closely related species, $U$. lactuca, are composed of cellulose and linear $\beta-1,4$ xyloglucans [3]. Methylation analysis of native and chemically modified ulvan indicated that this polysaccharide is composed of 1,4 and 1,2,4-linked rhamnose 3-sulfate, 1,4- and terminally-linked glucuronic acid and 1,4-linked xylose partially sulfated on O-2 [4]. Previous chemical studies on the sequence of these sugars in $U$. lactuca ulvan showed the presence of a majority of 4-O-( $\beta$-D-glucuronosyluronic acid)-L-rhamnose and small quantities of two other aldobiouronic acids tentatively identified as 3-O- and 4- $O$-(D-glucuronosyluronic acid)-D-xylose [5]. An acidic tetrasaccharide identified as D-glucuronosyluronic acid-( $\rightarrow 4)$-L-rhamnosyl-( $\rightarrow 3 / 4)$-Dglucuronosyluronic acid-( $\rightarrow 3)$-D-xylose and particularly the trisaccharide L-rhamnosyl-( $1 \rightarrow 4)$-D-xylosyl-(1 $\rightarrow 3$ )-D-glucose, obtained after partial acid hydrolysis of desulfated and carboxy-reduced ulvan, demonstrated the association of the three different sugars in the polysaccharide [5]. Ulvan is part of the polysaccharide that resists degradation by human digestive enzymes (dietary fibers) in the edible seaweed "sea-lettuce" [6,7] and can form weak gels in the presence of borate and calcium ions in a slightly alkaline environment $[2,8,9]$. In order to determine sugar sequences of this polysaccharide, oligosaccharides were generated by mild acid hydrolysis of native and chemically desulfated ulvan from $U$. "rigida" [4] and their chemical structure established by NMR analysis. The ${ }^{13} \mathrm{C}$ and ${ }^{1} \mathrm{H}$ NMR signal assignments of the major disaccharide obtained, the aldobiuronic acid 4- $O$-( $\beta$-D-glucuronosyluronic acid)-Lrhamnose, have already been reported [2] and we now report on the chemical structure of sulfated or branched oligosaccharides.

\section{Materials and methods}

Oligosaccharides. - Native and desulfated ulvan from $U$. " rigida' [1,4] were hydrolyzed with $0.1 \mathrm{M} \mathrm{TFA}$ at $100{ }^{\circ} \mathrm{C}$ for $75 \mathrm{~min}$. Oligosaccharides were recovered as described [2] after DEAE-Sepharose CL6B (17.5 × $3.4 \mathrm{~cm}$, Pharmacia) and Bio-Gel P2 (GPC, $96 \times 2.6 \mathrm{~cm}$, Bio-Rad) chromatographies with orcinol colorimetry or differential refractive index detection. Elution of the oligosaccharides from GPC was achieved with deionized water for neutral fractions and with $\mathrm{NaNO}_{3}(0.1 \mathrm{M})$ for charged oligosaccharides and is expressed as $K_{\mathrm{av}}\left[K_{\mathrm{av}}=\left(V_{\mathrm{e}}-V_{0}\right) /\left(V_{\mathrm{t}}-V_{0}\right)\right.$ with $V_{\mathrm{t}}, V_{0}$ being the total and void volume of the column and $V_{\mathrm{e}}$ the elution volume of the sample]. Fractions corresponding to oligosaccharide peaks were pooled, concentrated, and desalted by permeation through Sephadex G10 $(100 \times 1.6 \mathrm{~cm}$, Pharmacia $)$ eluted with deionized water and freeze-dried.

NMR analysis. $-{ }^{13} \mathrm{C}$ and ${ }^{1} \mathrm{H}$ NMR spectra of oligosaccharide solutions in $\mathrm{D}_{2} \mathrm{O}$ were recorded on a Bruker ARX 400 spectrometer. Carbon and proton chemical shifts of polymers were referenced to acetone assigned to 31.4 and $2.225 \mathrm{ppm}$, respectively. Oligosaccharides were deuterium-exchanged twice in $99.9 \% \mathrm{D}_{2} \mathrm{O}$ before solubilization in $0.5 \mathrm{~mL} 100 \% \mathrm{D}_{2} \mathrm{O}$ with a trace of acetone as internal reference. Non-exchangeable proton assignments of oligosaccharides and sugar sequences were determined from 2D, COSY90, COSY-Relay, COSY-DQF, TOCSY (HOHAHA), and NOESY spectra with water suppression using the conventional pulse sequences provided by Bruker. Carbon 
chemical shifts were determined from ${ }^{1} \mathrm{H}_{-}{ }^{13} \mathrm{C}$ HMQC and HMQC-TOCSY experiments. The $\mathrm{pD}$ values were measured with a $\mathrm{pH}$ electrode calibrated with aqueous buffer solutions and without correction for the deuterium.

\section{Results and discussion}

Oligosaccharides. - Oligosaccharides from native ulvan were fractionated into neutral and charged fractions by chromatography through DEAE-Sepharose CL6B. The charged fractions were eluted into two major populations by 0.15 and $0.40 \mathrm{M} \mathrm{NaCl}$ in a 0 to $1 \mathrm{M}$ gradient. Only the neutral and the charged oligosaccharides eluting first were further studied. The neutral population was fractionated on Bio-Gel P2 into several oligosaccharides. The major one, eluting at $K_{\text {av }} 0.47$, was identified by NMR spectroscopy as the aldobiuronic acid $\beta$-D-glucuronosyluronic acid- $(1 \rightarrow 4)_{-L}$-rhamnose [2]. The chemical shift for $\mathrm{H}-5 / \mathrm{C}-5$ and $\mathrm{H}-4 / \mathrm{C}-4$ reported in ref. [2] have been reversed in agreement with published data [10] and results obtained from oligosaccharides in this study (see below). Other oligosaccharides eluted at $K_{\mathrm{av}} 0.67,0.57,0.38$, and 0.16 , and only the oligomer eluting at $K_{\text {av }} 0.38$, referred to as $\mathbf{N 1}$, was studied further. The charged population was fractionated on Bio-Gel P2 into one major spreading peak probably due to excess of salts, and only the portion of the peak eluting at $K_{\text {av }} \sim 0.4$ (referred to as N2) was studied further. After partial acid hydrolysis of desulfated ulvan, neutral and charged oligomers were obtained as above. The neutral population yielded two major peaks on chromatography through Bio-Gel P2 with $K_{\text {av }}$ of 0.81 and 0.71 . Only the latter oligosaccharide was studied and is referred to as D1. The charged oligosaccharides eluted from the anion exchanger into a major wide fraction and a smaller population eluting with $0.1-0.3 \mathrm{M}$ and $0.5 \mathrm{M} \mathrm{NaCl}$, respectively. Only the first population was studied and yielded several peaks on chromatography through Bio-Gel P2. The major one $\left(K_{\mathrm{av}} 0.61\right)$ was identified by NMR spectroscopy as the aldobiuronic acid, $\beta$-D-glucuronosyluronic acid-( $1 \rightarrow 4)$-L-rhamnose [2]. Two minor peaks eluted at $K_{\text {av }} 0.37$ and 0.27 were studied further and are referred to as D2 and D3, respectively.

From the chemical composition of the parent polysaccharides [4], the oligosaccharides were expected to be composed of only xylose, rhamnose, and glucuronic acid.

Determination of the chemical structure of the neutral oligosaccharides D1 and N1. -The ${ }^{1} \mathrm{H}$ NMR spectrum of oligosaccharide D1 shows 4 major signals in the region of the anomeric protons $(5.195,4.926,4.921,4.586 \mathrm{ppm}$, see Fig. 1) with intensities indicating that this oligomer is a disaccharide. From their chemical shifts and $J_{l, 2}$ coupling constants (Table 1) two of the anomeric signals (5.195 and $4.586 \mathrm{ppm}$ ) were attributed to a reducing-end xylose in the $\alpha$ and $\beta$ configuration [11]. The two overlapping anomeric signals (4.926 and $4.921 \mathrm{ppm}$ ) with a small coupling constant (1.9 $\mathrm{Hz}$ ) and the methyl proton $(1.317 \mathrm{ppm})$ were attributed to $\mathrm{H}-1$ of an $\alpha$-rhamnose residue [11] affected by the configuration of the reducing end sugar to which it is linked and its H-6, respectively. The effect of the reducing-end on the chemical shifts of the rhamnose protons is observed up to H-3, 2D COSY90 and Relay-COSY allowed the full chemical shift assignment of all the protons in this disaccharide (Table 1) and the coupling constants measured are in agreement with those reported in the literature [11]. The 


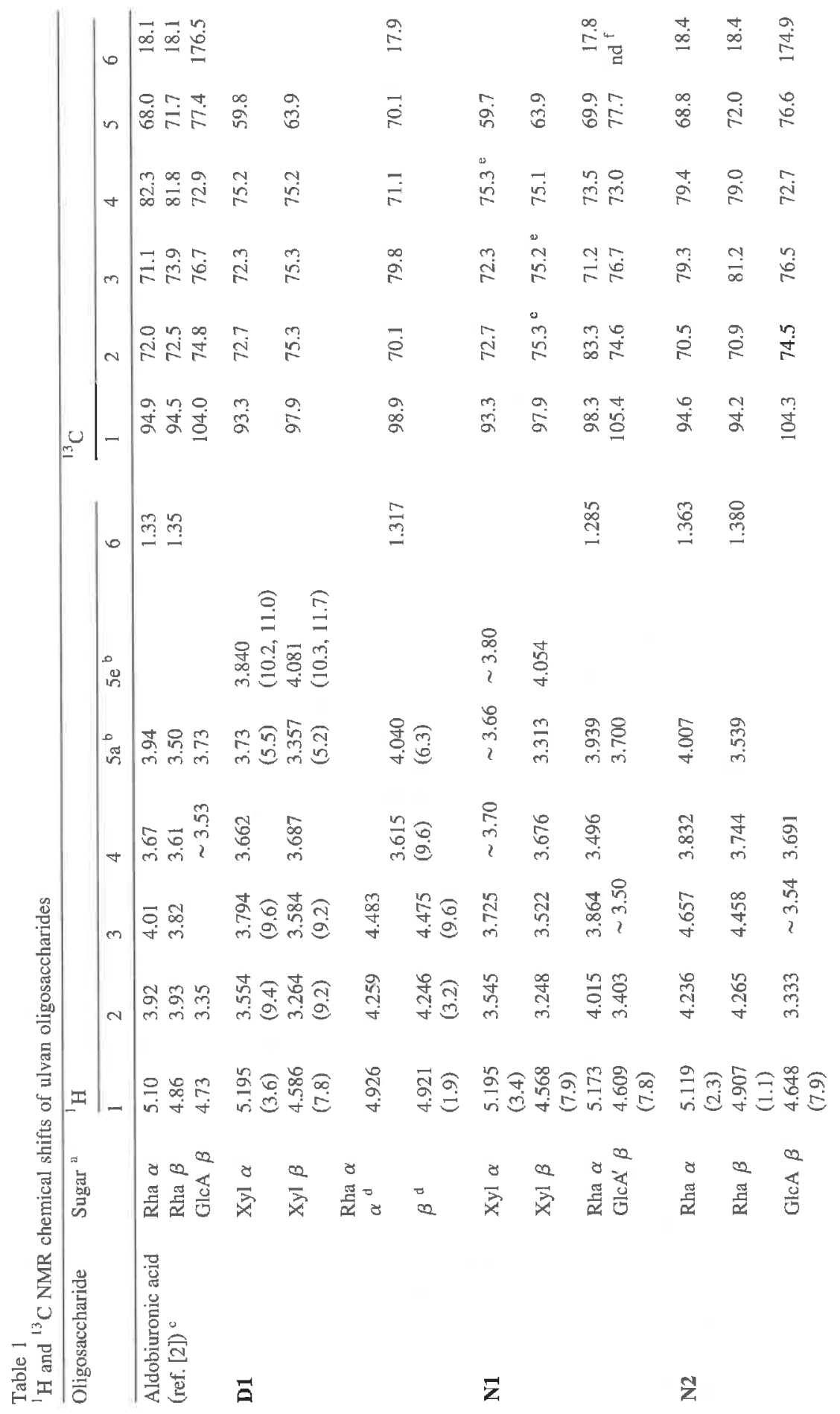




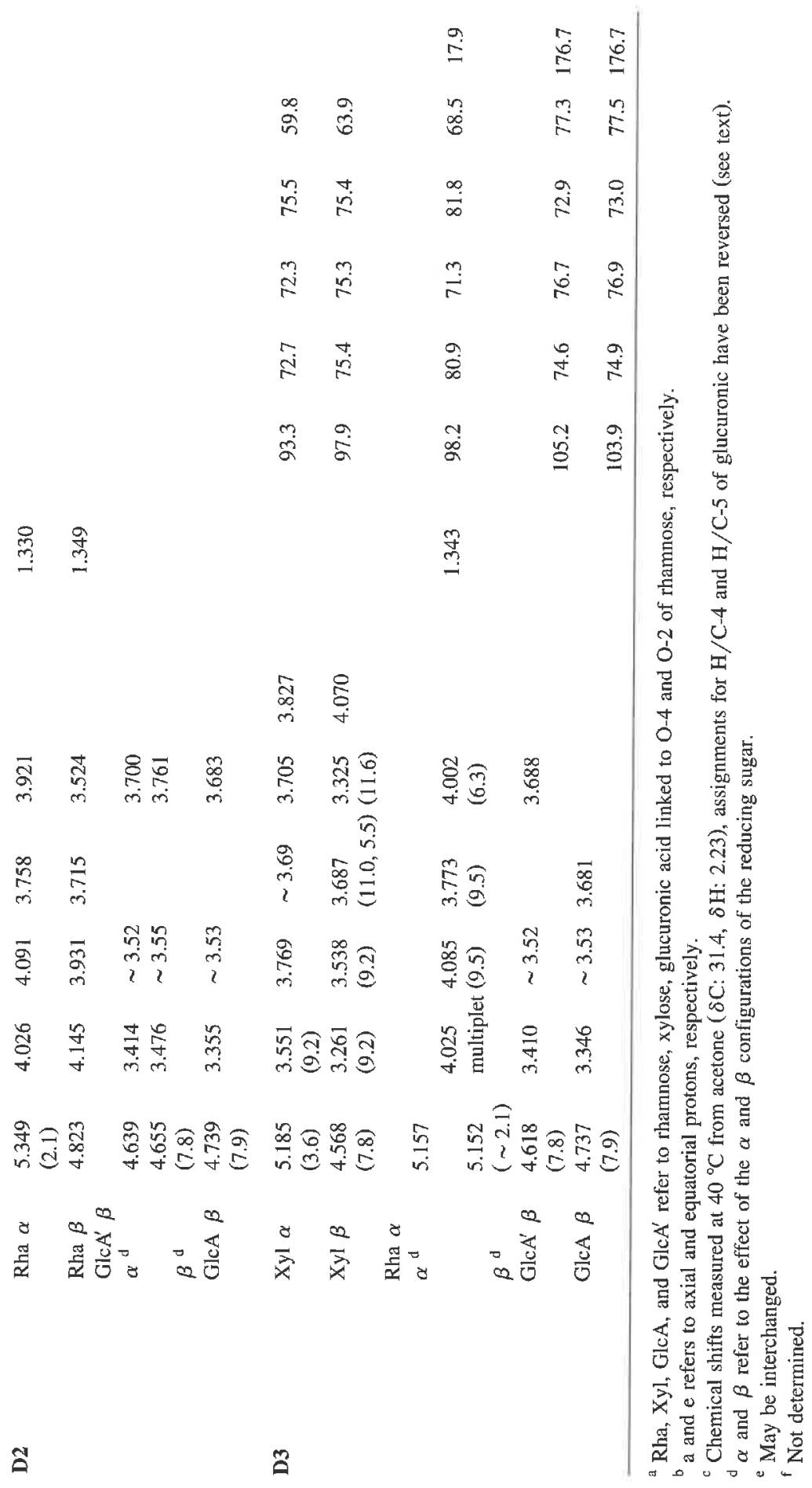




$$
\alpha-L-R h a 1->4 \text { D-Xyl }
$$

D1

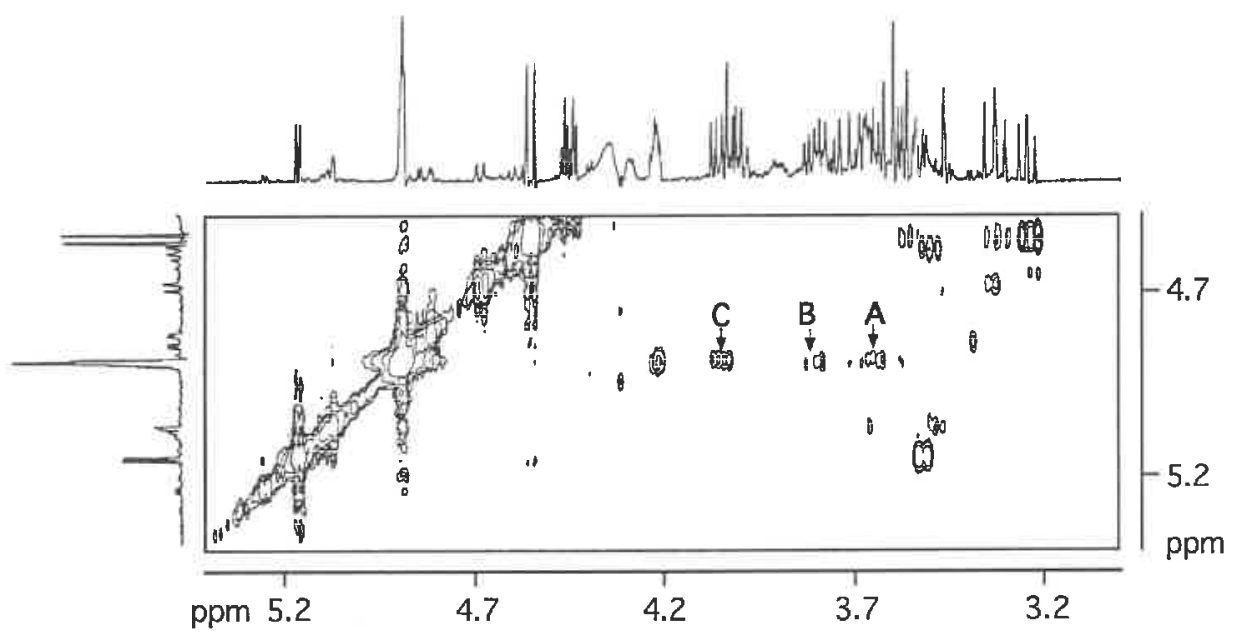

Fig. 1. Part of 2D NOESY spectrum of oligosaccharide D1 at $55^{\circ} \mathrm{C}$ with a mixing time of $700 \mathrm{~ms}$. Along the $\mathrm{F} 1$ and $\mathrm{F} 2$ axes are high resolution $1 \mathrm{D}$ spectra of the oligomer. The following inter-residue cross-peak are

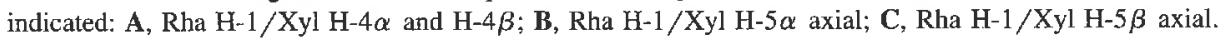

linkage of rhamnose to the reducing-end xylose was established by a NOESY experiment (Fig. 1). Cross-peaks were observed between rhamnose $\mathrm{H}-1$ and xylose $\mathrm{H}-4 \alpha / \beta$ and $\mathrm{H}-5^{\prime} \alpha / \beta$ clearly indicating the rhamnose linkage to $\mathrm{O}-4$ of xylose. No NOE was observed between rhamnose H-1 and rhamnose H-3 and H-5 and, together with the $J_{1,2}$ coupling constant, confirmed the $\alpha$ configuration of the sugar [12]. Oligosaccharide D1 was thus deduced to be $\alpha$-L-rhamnosyl- $(1 \rightarrow 4)$-D-xylose. The ${ }^{13} \mathrm{C}$ NMR chemical shifts were deduced from an HMQC experiment (Table 1).

Oligosaccharide $\mathbf{N 1}$ gave a ${ }^{1} \mathrm{H}$ NMR spectrum with 4 major anomeric protons at $5.195\left(J_{1,2} 3.4 \mathrm{~Hz}\right), 4.568\left(J_{l, 2} 7.9 \mathrm{~Hz}\right), 5.173$ and $4.609 \mathrm{ppm}\left(J_{1,2} 7.8 \mathrm{~Hz}\right)$ (see Fig. 2) which, based on their intensities, indicated that N1 is a trisaccharide. Three of these anomeric protons corresponded to those of rhamnose and reducing end xylose of oligosaccharide D1. The identity of the last sugar residue was determined to be $\beta$-GlcA from its coupling network and by comparison with chemical shifts obtained for the aldobiuronic acid, $\beta$-D-GlcA- $(1 \rightarrow 4)$-L-rhamnose (Table 1$)$. All the proton chemical shifts were determined by COSY-DQF and TOCSY experiments (Table 1). The linkage of these sugars was determined from the NOESY cross-peaks observed between $\mathrm{H}-1$ of the glucuronic acid residue with rhamnose $\mathrm{H}-2$ and $\mathrm{H}-1$ of rhamnose with xylose $\mathrm{H}-4 \alpha$ and $\mathrm{H} 4-\beta$ (Fig. 3). Thus, this trisaccharide is identified as $\beta$-D-GlcA-(1 $\rightarrow 2)-\alpha$-L-Rha$(1 \rightarrow 4)$-D-Xyl. The ${ }^{13} \mathrm{C}$ NMR chemical shifts were attributed from HMQC and HMQCTOCSY experiments and by comparison with chemical shifts observed for these carbons in oligosaccharides $\mathbf{N 2}$ and D3 (Table 1). 


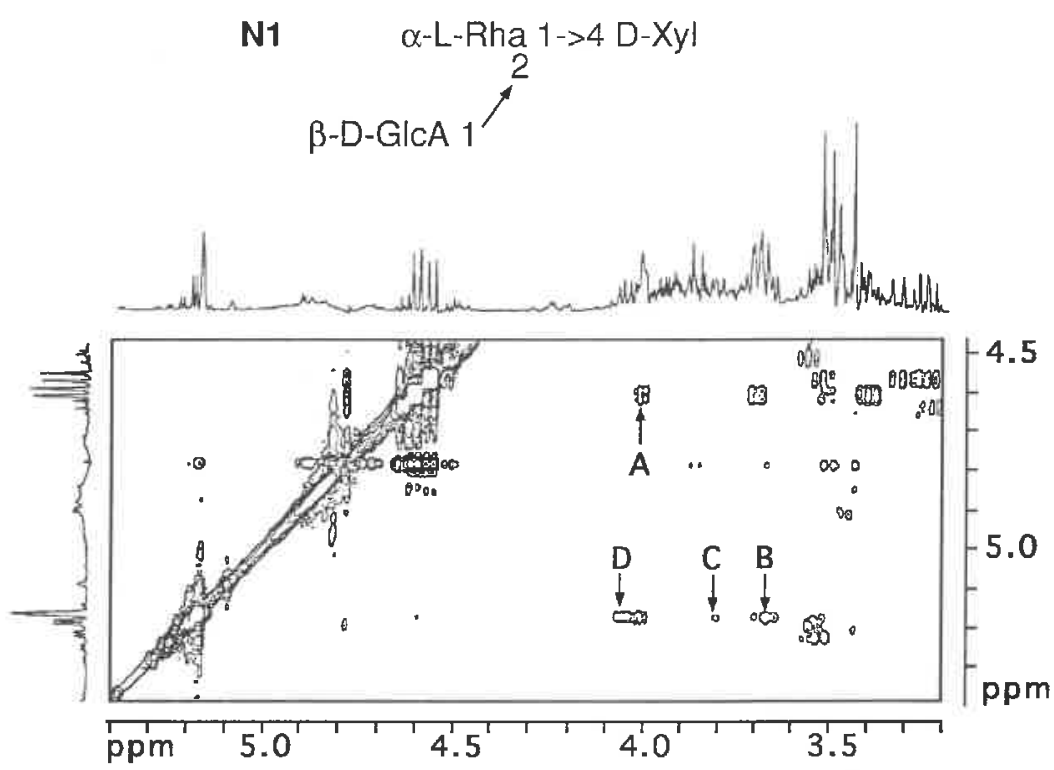

Fig. 2. Part of 2D NOESY spectrum of oligosaccharide N1 at $55^{\circ} \mathrm{C}(\mathrm{pD} 6.8$ ) with a mixing time of $500 \mathrm{~ms}$. Along the $\mathrm{F} 1$ and $\mathrm{F} 2$ axes are high resolution $1 \mathrm{D}$ spectra of the oligomer. The following inter-residue cross-peak are indicated: A, GlcA H-1/Rha H-2; B, Rha H-1/Xyl H- $4 \alpha$ and H-4 $\beta$; C, Rha H-1/Xyl H-5 $\alpha$ axial; D, Rha $\mathrm{H}-1 / \mathrm{Xyl} \mathrm{H}-5 \beta$ axial.

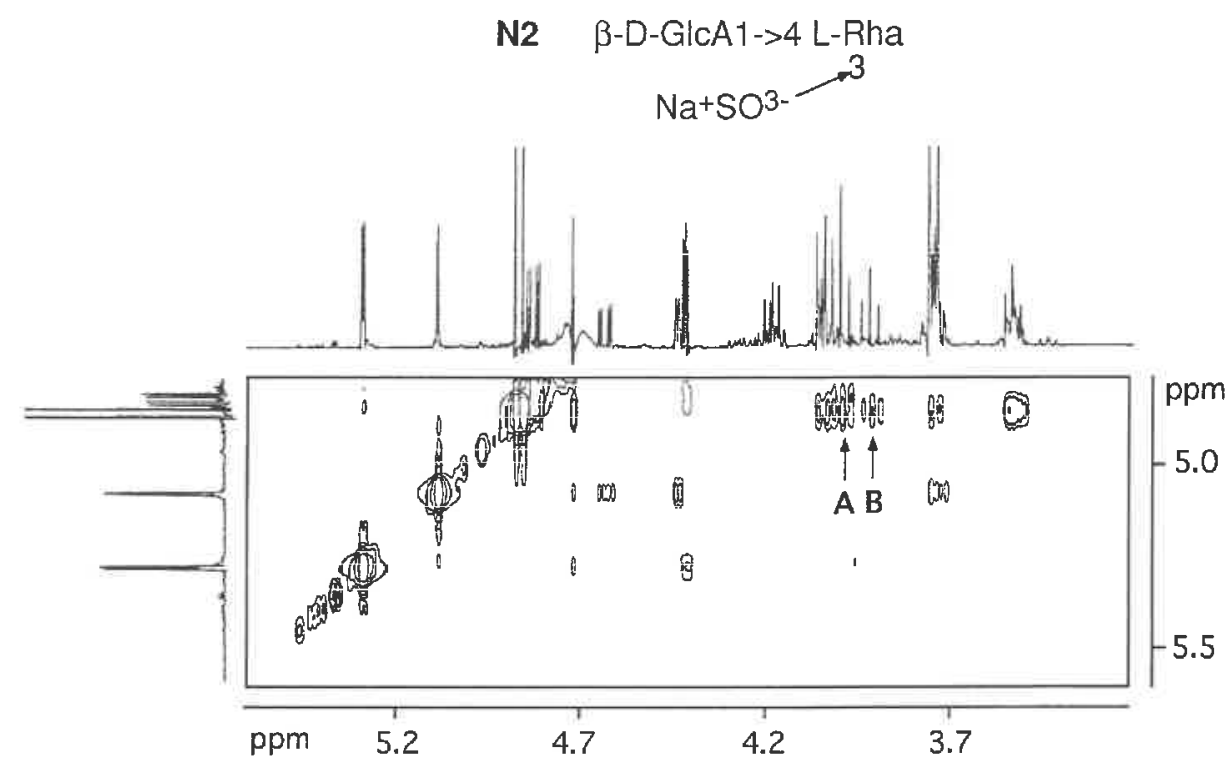

Fig. 3. Part of 2D NOESY spectrum of oligosaccharide $\mathrm{N} 2$ at $55^{\circ} \mathrm{C}$ (pD 3.5) with a mixing time of $700 \mathrm{~ms}$. Along the F1 and F2 axes are high resolution 1D spectra of the oligomer. The following inter-residue cross-peak are indicated: A, GlcA H-1/Rha H-4 $\alpha$; B, GlcA H-1/Rha H-4 $\beta$. 
Determination of the chemical structure of the oligosaccharides $\mathbf{N 2}, \mathbf{D} 2$, and $\mathbf{D 3}$ eluted with a salt gradient from the anion exchanger.- The higher charge density of these oligosaccharides is due to a greater amount of uronic acids and/or the presence of sulfate groups. Oligosaccharide $\mathbf{N} 2$ gave a ${ }^{1} \mathrm{H}$ NMR spectrum (see Fig. 3 ) showing 3 anomeric protons of chemical shifts close to those of the aldobiuronic acid ( $\beta$-Dglucuronosyluronic acid-( $\rightarrow 4$ )-L-rhamnose) (Table 1). Taking into account their intensity, N2 is a disaccharide with rhamnose at the reducing-end. The chemical shift of the other protons was determined by COSY-DQF and TOCSY experiments (Table 1). Non-first-order couplings between the glucuronic acid protons were observed (particularly $\mathrm{H}-2$ and $\mathrm{H}-5$, data not shown) and were probably related to the virtual long-range spin-spin couplings described for this sugar [13]. Such couplings were also observed for the aldobiuronic acid (data not shown). As for the latter acidic disaccharide, the glucuronic acid in N2 is linked to rhamnose O-4 as demonstrated by the cross-peaks observed on the NOESY contour plot (Fig. 3) between glucuronic $\mathrm{H}-1$ / rhamnose H-4 $\alpha$ and $\beta$. A minor temperature effect was seen for the chemical shift of $\mathrm{H}-5$ of the glucuronic acid residue ( $+0.01 \mathrm{ppm}$ from 56 to $25^{\circ} \mathrm{C}$ ) but, as reported [10], strong effects were seen for glucuronic acid protons at different $\mathrm{pD}(+0.05,+0.02,+0.06$ and $+0.29 \mathrm{ppm}$ for $\mathrm{H}-1,2,3 / 4$ and 5 , respectively between $\mathrm{pD} 7.6$ and 2.3). Similar effects of $\mathrm{pD}$ were observed for the aldobiuronic acid $\mathrm{H}-5$ and $\mathrm{H}-3 / 4$ of glucuronic acid (data not shown) and indicates the strong influence of the ionic status of the carboxyl group on the conformation of the glucuronic acid residue. No effect was observed for the rhamnose protons. The ${ }^{13} \mathrm{C}$ NMR chemical shifts were determined for this oligosaccharide by HMQC and HMQC-TOCSY experiments as for oligosaccharide N1 (Table

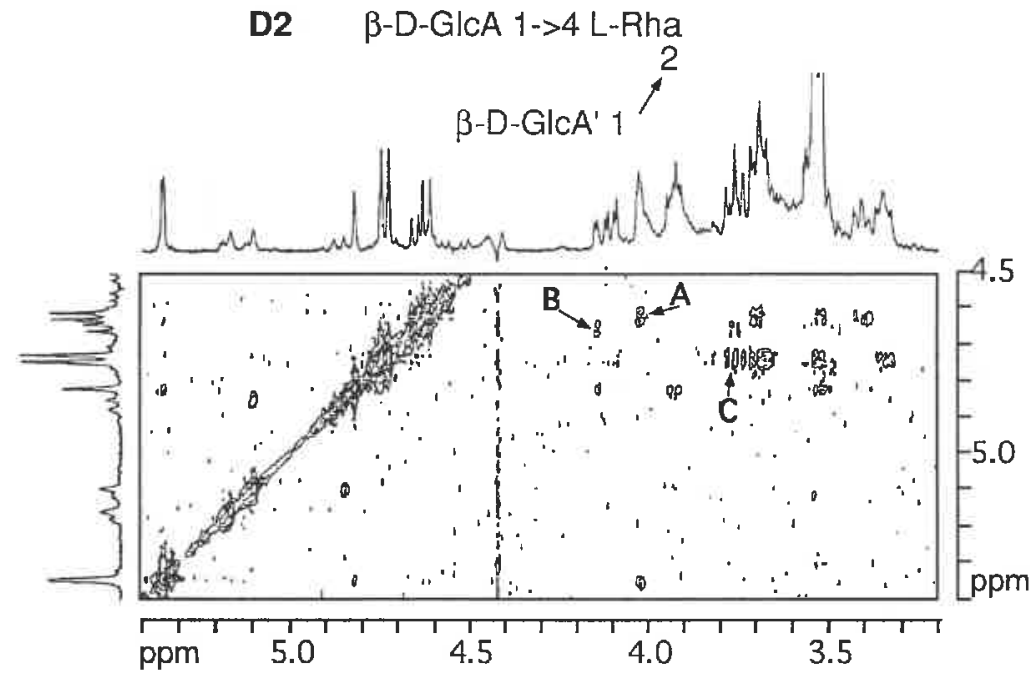

Fig. 4. Part of 2D NOESY spectrum of oligosaccharide $\mathrm{D} 2$ at $55^{\circ} \mathrm{C}(\mathrm{pD} 7.8$ ) with a mixing time of $700 \mathrm{~ms}$. Along the F1 and F2 axes are high resolution 1D spectra of the oligomer. The following inter-residue cross-peak are indicated: A, GlcA' H-1/Rha H- $\alpha 2$; B, GlcA H-1/Rha H- $\beta 2$; C, GlcA H-1/Rha H-4; the prime denotes the GlcA linked to $\mathrm{O}-2$ of Rha. 
1). Considering the marked downfield shifts of rhamnose $\mathrm{H}-3 \alpha / \beta, \mathrm{H}-2 \alpha / \beta$, and $\mathrm{H}-4 \alpha / \beta$ resonances (about $0.65,0.33$, and $0.15 \mathrm{ppm}$, respectively), the major downfield shift for $\mathrm{C}-3 \alpha / \beta$ ( 8.2 and $7.3 \mathrm{ppm}$ for the $\alpha$ and $\beta$ configuration, respectively) and the upfield shifts for the $\mathrm{C}-2 \alpha / \beta$ and $\mathrm{C}-4 \alpha / \beta$ resonances (1.6 and $2.9 \mathrm{ppm}$, respectively) compared to the respective nuclei in the aldobiuronic acid (Table 1), O-3 of rhamnose is deduced to be the site of sulfate substitution. Oligosaccharide $\mathbf{N 2}$ is thus identified as $\beta$-D-glucuronosyluronic acid-(1 $\rightarrow 4)$-L-rhamnose 3-sulfate.

Oligosaccharide D2 showed a ${ }^{1} \mathrm{H}$ NMR spectrum with 5 anomeric signals at 5.349 $\left(J_{l, 2}, 2.1 \mathrm{~Hz}\right), 4.823,4.639\left(J_{l, 2}, 7.8 \mathrm{~Hz}\right), 4.655\left(J_{l, 2}, 7.8 \mathrm{~Hz}\right)$ and $4.739 \mathrm{ppm}\left(J_{1,2}, 7.9\right.$ $\mathrm{Hz}$ ) (see Fig. 4) which, taking their intensity into account, corresponded to a trisaccharide with one residue markedly affected by the configuration of the reducing end sugar. The different saccharides were identified as two $\beta$-D-GlcAs and one reducing end rhamnose from the proton chemical shifts and coupling constants determined by COSY-DQF and TOCSY experiments (Table 1). Some of the chemical shifts presented similarities with those of the GlcAs of oligosaccharide N1 and of the aldobiuronic acid (Table 1). Proton resonances of the $\beta$-rhamnose residue were close to those reported for a $\beta$ - $(1,2,4)$-linked rhamnose residue in a polysaccharide extracted from the stipules of the tree Musanga cercropoides [14]. Linkages of the sugars were deduced from the NOESY experiment (Fig. 4): GlcAs are linked to O-4 and O-2 of the rhamnose located at the reducing-end. The protons of the GlcA linked to O-2 of rhamnose are markedly affected by the anomeric configuration of the reducing end sugar. The NOESY cross-peaks between the GlcA doublet at $4.655 \mathrm{ppm}$ with $\mathrm{H}-2$ of $\beta$-rhamnose and that at $4.639 \mathrm{ppm}$ with $\mathrm{H}-2$ of $\alpha$-rhamnose clearly demonstrated it (Fig. 4). Such reducing end configurations have only a minor effect on the anomeric proton of the GlcA linked to

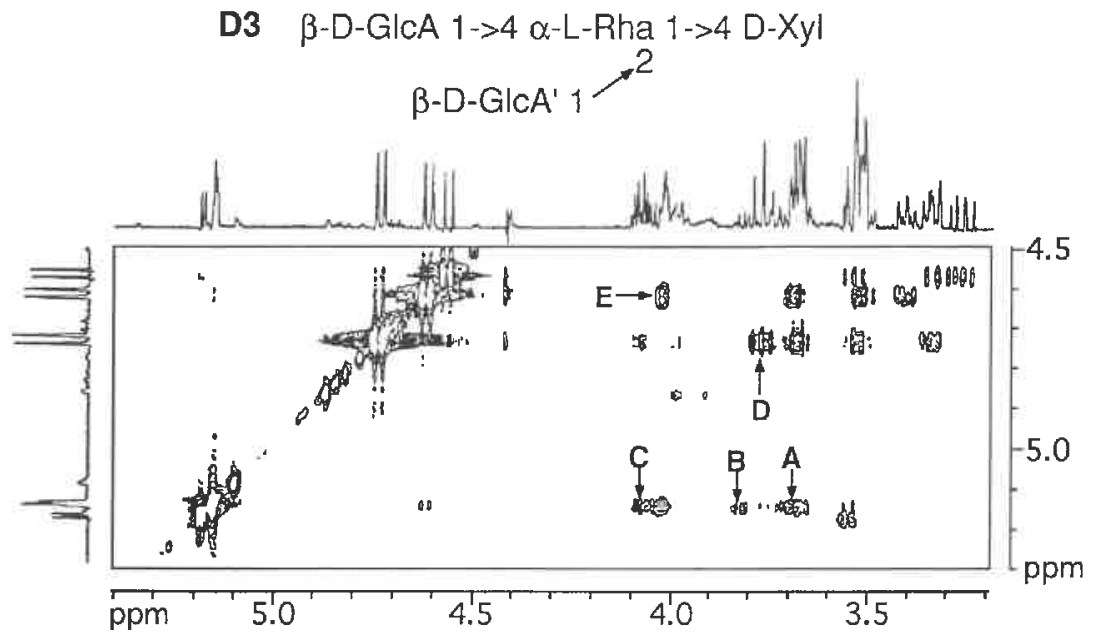

Fig. 5. Part of 2D NOESY spectrum of oligosaccharide $\mathbf{D 3}$ at $55^{\circ} \mathrm{C}$ (pD 7.9) with a mixing time of $700 \mathrm{~ms}$. Along the F1 and F2 axes are high resolution $1 \mathrm{D}$ spectra of the oligomer. The following inter-residue cross-peak are indicated: A, Rha H-1/Xyl H- $\alpha-\beta$; B, Rha $\mathrm{H}-1 / \mathrm{Xyl} \mathrm{H}-5 \alpha$ axial; C, Rha H-1/Xyl H-5 $\beta$ axial; D, GlcA H-1/Rha H-4; E, GlcA H-1/Rha H-2; the prime denotes the GlcA linked to O-2 of Rha. 
O-4 of rhamnose: only a small enlargement at the base of the doublet signal at 4.739 ppm can be observed. This oligosaccharide is thus identified as $\beta$-D-glucuronosyluronic acid-( $1 \rightarrow 4)$-[ $\beta$-D-glucuronosyluronic acid-( $\rightarrow 2)$-]-L-rhamnose. The low oligosaccharide concentration precluded $1 \mathrm{D}{ }^{13} \mathrm{C}$ and $2 \mathrm{D}{ }^{1} \mathrm{H} /{ }^{13} \mathrm{C}$ correlation spectra to be recorded and thus, carbon chemical shifts were not determined.

Oligosaccharide D3 ${ }^{1} \mathrm{H}$ NMR spectrum shows 5 anomeric signals and considering their intensity, corresponds to a tetrasaccharide (see Fig. 5). Two glucuronic acids, one rhamnose and one reducing end xylose residues were identified by COSY90 and RELAY-COSY experiments (Table 1). ${ }^{1} \mathrm{H}$ NMR chemical shifts of $\mathbf{D 3}$ were close to those for the glucuronic acids and some of the rhamnose protons of oligosaccharide $\mathbf{D} 2$ and for the xylose and some of the rhamnose protons of oligosaccharide N1 (Table 1).

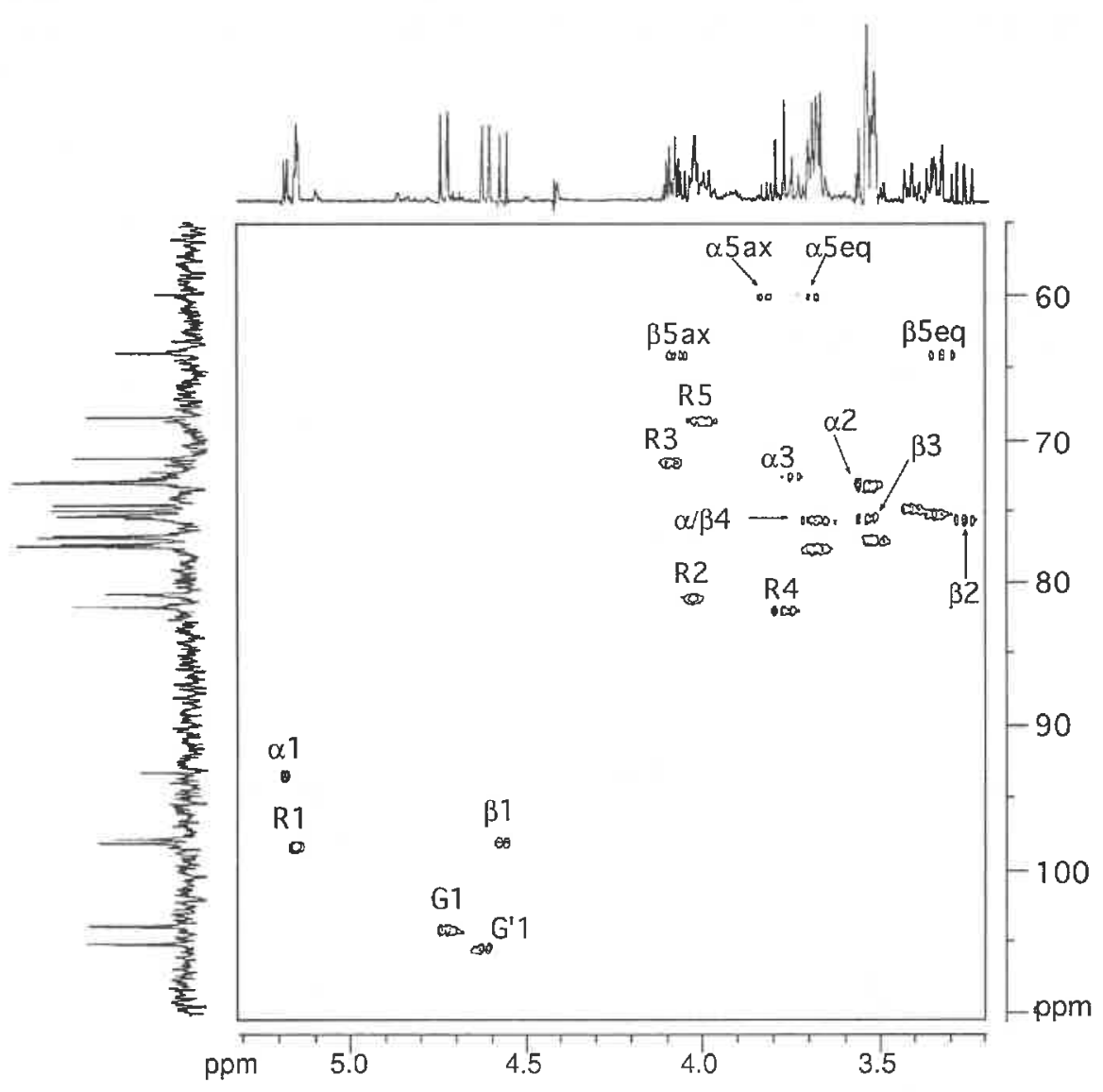

Fig. 6, 2D ${ }^{1} \mathrm{H}-{ }^{13} \mathrm{C}$ chemical shift correlation spectroscopy (HMQC) contour plot obtained for oligosaccharide D3 at $55^{\circ} \mathrm{C}$. Letters R, G, $\mathrm{G}^{\prime}, \alpha$ and $\beta$ refer to Rha, GlcA linked to O-4 of Rha, GlcA linked to O-2 of Rha, $\mathrm{Xyl} \alpha$ and $\mathrm{Xy} 1 \beta$, respectively; numbers correspond to the proton/carbon in the residues; ax and eq refer to axial and equatorial, respectively. High resolution $1 \mathrm{D}{ }^{1} \mathrm{H}$ and ${ }^{13} \mathrm{C}$ spectra are represented along the F2 and $\mathrm{F} 1$ axes, respectively. 

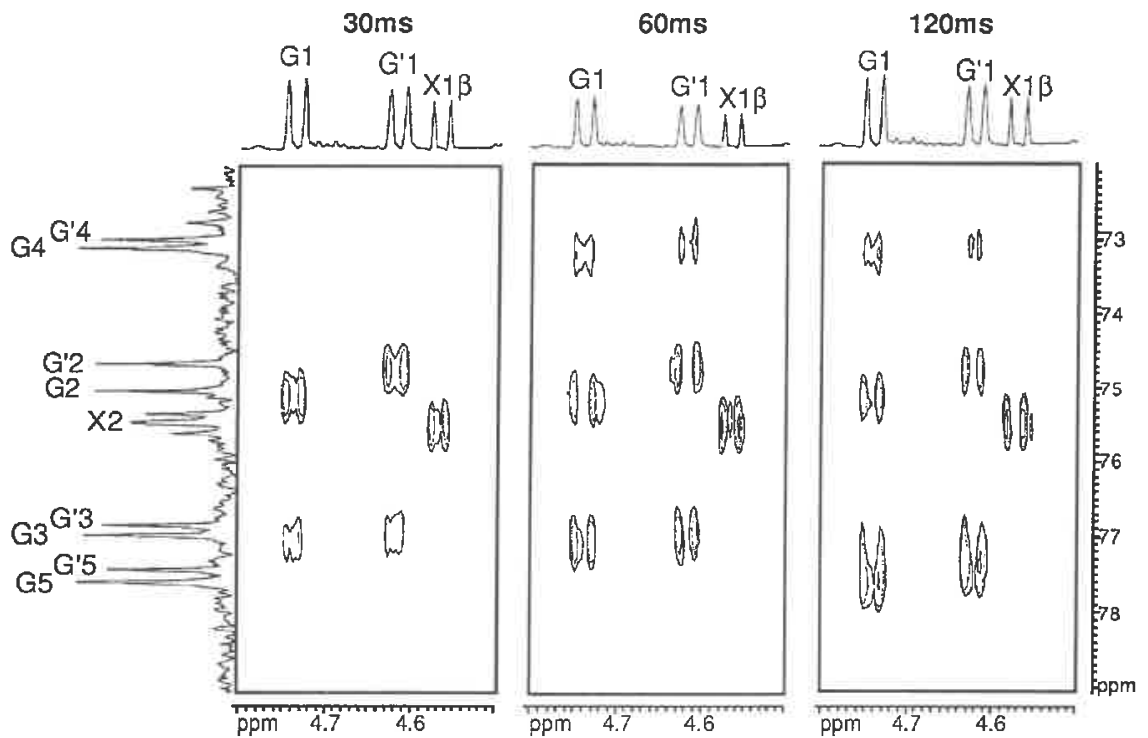

Fig. 7. Part of 2D HMQC-TOCSY of oligosaccharide $\mathbf{D} 3$ at $55{ }^{\circ} \mathrm{C}$ in $\mathrm{D}_{2} \mathrm{O}$. Symbols are as in Fig. 6. High resolution ${ }^{1} \mathrm{H}$ and ${ }^{13} \mathrm{C}$ NMR spectra are shown along the $\mathrm{F} 2$ and $\mathrm{F} 1$ axes, respectively.

The NOESY experiment allowed the determination of the linkages between the sugars (Fig. 5). Thus, glucuronic acid residues are linked to O-4 and O-2 of rhamnose itself linked to $0-4$ of xylose at the reducing end. This oligosaccharide is identified as $\beta$-D-glucuronosyluronic acid- $(1 \rightarrow 4)$-[ $\beta$-D-glucuronosyluronic acid-( $1 \rightarrow 2)$-]- $\alpha$-Lrhamnosyl-( $(\rightarrow 4)$-D-xylose. Most of the ${ }^{13} \mathrm{C}$ NMR chemical shifts were attributed by a HMQC experiment (Table 1, Fig. 6). HMQC-TOCSY experiments with different mixing times (30-120 ms) allowed for the unambiguous attribution of the carbons C2-C5 of the two glucuronic acid residues (Fig. 7).

\section{Conclusion}

The oligosaccharides obtained after partial acid hydrolysis of native and desulfated ulvan allowed identification of sugar sequences in ulvan and to confirm linkages and substitutions determined by methylation analysis of the native and chemically modified polysaccharide [4]. In agreement with literature data obtained from $U$. lactuca [5], the major oligosaccharide obtained from $U$. "rigida" ulvan was identified in a previous study to be the aldobiuronic acid, $\beta$-D-glucuronosyluronic acid-( $\rightarrow 4)$-L-rhamnose [2] that we propose to refer to as ulvanobiuronic acid for simplicity. Other basic repeating sequences isolated from the acid hydrolysate of native and desulfated ulvan provided the definitive proof that all three sugars are linked together in the same polymer and that branching by glucuronic acid occurs on $\mathrm{O}-2$ of rhamnose. Considering that glucuronic acid is found by methylation analysis to be located for a good part at non-reducing ends 
of ulvan [4], the present data suggest that the branch is composed of single glucuronic acid residue. However, future work using milder and more specific degradation methods are required to determine the composition and the length of the side-chain in the native polymer that may have been partially degraded by the hydrolysis condition used in this study. Rhamnose is often found in bacterial exopolysaccharides [15] or plant pectic polysaccharides [16] but branching on O-2 of a $(1 \rightarrow 4)$-linked $\alpha$-L-rhamnose residue by a $\beta$-D-glucuronic acid residue has, to our knowledge, only been described for the exopolysaccharide produced by the bacterium Arthrobacter sp. [17]. Apart from the ulvanobiuronic acid, the oligosaccharides obtained in this study differ from those of Haq and Percival [5]. The only common features between these works are the linkages of thamnose to O-4 of D-xylose and that of glucuronic acid to O-4 of rhamnose. In contrast to the branching on $\mathrm{O}-3$ of rhamnose deduced by these authors from methylation analysis, no such branching was observed in the oligosaccharides isolated in the present work. Concerning the site of sulfate substitution on ulvan, the comparison between ${ }^{1} \mathrm{H}$ and ${ }^{13} \mathrm{C}$ NMR chemical shifts of ulvanobiuronic acid and that of oligosaccharide $\mathbf{N} 2$ clearly confirmed the location of sulfate group on O-3 of rhamnose determined by chemical analysis [4]. Unfortunately, oligosaccharides containing sulfated xylose residues were not isolated at this time and the site of sulfation on this residue only rely on data obtained from chemical analyses. Further works is under way to determine if this sulfation and sugar linkages are common to the ulvan from different species of Ulva.

\section{Acknowledgements}

This work was funded in part by the European Community under the contract AIR CT92-0518.

\section{References}

[1] B. Ray and M. Lahaye, Carbohydr. Res., 274 (1995) 251-261.

[2] M. Lahaye, B. Ray, S. Baumberger, B. Quemener, and M.A.V. Axelos, Hydrobiologia, in press.

[3] M. Lahaye, D. Jegou, and A. Buleon, Carbohydr. Res., 262 (1994) 115-125.

[4] B. Ray and M. Lahaye, Carbohydr. Res., 274 (1995) 313-318.

[5] Q.N. Haq and E. Percival, in H. Barnes (Ed.), Some Contemporary Studies in Marine Sciences, George Allen and Unwin Ltd., London, 1966, pp 355-368.

[6] M. Lahaye and D. Jegou, J. Appl. Phycol., 5 (1993) 195-200.

[7] C. Bobin-Dubigeon, M. Lahaye, and J.-L. Barry, J. Sci. Food Agric., submitted for publication.

[8] A. Haugh, Acta Chem. Scand., Ser. B, 30 (1976) 562-566.

[9] M. Lahaye and M.A.V. Axelos, Carbohydr. Polym., 22 (1993) 261-265.

[10] L. Dantas, J. Courtois, B. Courtois, J.-P. Seguin, C. Gey, and A. Heyraud, Carbohydr. Res., 265 (1994) $303-310$.

[11] K. Bock and H. Thøgersen, Ann. Rep. NMR Spectroscopy, 13 (1982) 1-57.

[12] J. Dabrowski, in W.R. Croasmun and R.M.K. Carlson (Eds.), Two-Dimensional NMR Spectroscopy, Applications for Chemists and Biochemists, 2nd edn., VCH Publishers, New York, 1994, pp 741-783.

[13] S. Saito, Y. Sasaki, T. Furumoto, S. Sumita, and T. Hinomoto, Carbohydr. Res., 258 (1994) 59-75.

[14] P.-E. Jansson, B. Lindberg, M. Ogunlesi, and T. Orebamjo, Carbohydr. Res., 214 (1991) 281-287. 
[15] L. Kenne and B. Lindberg, in G.O. Aspinall (Ed.), The Polysaccharides, Vol. 2, Academic Press, New York, 1983, pp 287-363.

[16] M. McNeil, A.G. Darvill, S.C. Fry, and P. Albersheim, Ann. Rev. Biochem., 53 (1984) 625-663.

[17] S.N. Senchenkova, Y.A. Knirel, L.M. Likhosherstov, A.S. Shashkov, V.N. Shibaev, L.A. Starukhina, and V.V. Deryabin, Carbohydr. Res., 266 (1995) 103-113. 
